\title{
ENFERMEDAD, DOLOR Y MUERTE EN DOS NOVELAS ESPAÑOLAS DEL SIGLO XXI
}

\author{
SICKNESS, PAIN AND DEATH IN TWO $21^{\mathrm{ST}}$ CENTURY SPANISH NOVELS
}

\author{
María de Alva Levy \\ Instituto Tecnológico de Monterrey. Monterrey, México \\ mdealva@itesm.mx
}

\begin{abstract}
Resumen: La enfermedad, el dolor y la muerte se vuelven marginación, pero también dignidad y solidaridad, un sitio de encuentro y reconciliación. Un milagro en equilibrio de Lucía Etxebarria e Historia del rey transparente de Rosa Montero tienen personajes enfermos o que sufren por dolor, que al final mueren. Ambas se contraponen al concepto de metaforización de la enfermedad, apelan a llamar las cosas por su nombre, lejos de eufemismos de cualquier índole. Las narradoras de estas historias se alejan de dicha metáfora y su actitud es la de la resistencia a través de la escritura.
\end{abstract}

Palabras clave: Novela, España, siglo XXI, cuerpo, mujeres.

\begin{abstract}
Sickness, pain and death represent marginalization, but also dignity and solidarity, a place of encounter and reconciliation. Lucía Etxebarria's Un milagro en equilibrio and Rosa Montero's Historia del rey transparente are two recent novels with characters that are either sick or in extreme pain, and die in the end. Both novels are opposed to the concept of metaphorization of sickness, and appeal to call things by their name, beyond euphemisms of any kind. The narrators form this stories move away from this metaphor and adopt an attitude of resistance through writing.
\end{abstract}

Keywords: Novel, Spain, Twenty-first Century, body, women.

Recibido: 04.04.2014. Aceptado: 23.09.2014.

T A ENFERMEDAD, el dolor y la muerte representan la expulsión del reino de Mlos sanos para ingresar en el mundo de los enfermos, un sitio de marginación al que se accede y del cual no se puede volver hasta que se haya 
recuperado. En el lugar del enfermo - primera parada antes de la muertese depende de otros para las necesidades básicas; hay también utensilios de diversos tipos para solventar algunos problemas físicos y existe una especie de reclusión que implica la pérdida de la normalidad, en el que se está en un lugar apartado, donde todo empeño está puesto en la recuperación del enfermo. "El dolor del cuerpo exige una completa atención. Cuando el que habla es el cuerpo enfermo, cuando los dolores son recurrentes, cualquier equilibrio o armonía en nuestra vida cotidiana se ve irremediablemente trastocada, herida" (Martínez Passarge, 2004: 2). Así, el enfermo se vuelve la no-persona, improductiva para la sociedad, sin función aparente.

Las novelas Un milagro en equilibrio de Lucía Etxebarria (2004) e Historia del rey transparente de Rosa Montero (2005) tienen personajes enfermos o que sufren por dolor, y que al final mueren. Ambas se contraponen al concepto de metaforización de la enfermedad como explica Susan Sontag, ambas apelan a llamar las cosas por su nombre, lejos de eufemismos de cualquier índole. Para Sontag, las enfermedades, sobre todo las de larga duración o crónicas, conllevan metáforas que tienen que ver con castigo, expiación o marca social, también contienen ideas románticas, pero pocas veces son tratadas como lo que son: enfermedades que responden a la biología propia del ser humano. "Las metáforas patológicas siempre han servido para reforzar los cargos que se le hacen a la sociedad por su corrupción o injusticia" (Sontag, 2003a: 101). Sin embargo, las narradoras de estas historias se alejan de dicha metáfora y su actitud es la de resistencia. A través de la escritura muestran dicho desapego.

La experiencia de la enfermedad es -como todo lo que atañe al cuerpode índole personal. Los demás pueden ver al enfermo, condolerse de él, ayudarle en lo posible, pero no pueden sustituir su experiencia. La medida del dolor y la enfermedad es variable. La intensidad con la que se vive no puede tener una exactitud precisa. Es decir, la subjetividad rige todos los parámetros al ser una práctica individual, irrepetible. Por su parte, en estas obras, la muerte es la pérdida del cuerpo y la entrada a la realidad del cadáver, con el fin del cuerpo se acaba la persona. Lejos de idealizaciones románticas o heroísmos, la muerte es simplemente el fin de la vida, aceptarla es parte de la condición humana.

En este texto se busca conferir las etapas del cuerpo durante la enfermedad con especificaciones en cuanto al dolor, así como la muerte. 


\section{El cuerpo enfermo}

En Un milagro en equilibrio es la madre de la narradora quien sufre la enfermedad y ella debe cuidarla, mientras que en la otra novela, la protagonista misma es la enferma. De cualquier forma, en ambas se transita por la experiencia de la enfermedad prolongada y eso les hace descubrir otros aspectos de la vida propia que no habían sido capaces de ver antes, como si la enfermedad les revelara algo escondido.

La enfermedad reinventa tiempo e introspección. La mirada viaja desde el pasado sano hasta el presente enfermo. El futuro se observa como un espacio lejano e incierto, como un tiempo en el cual no debe cavilarse. Por eso hay quienes conjugan el tiempo enfermedad sólo en presente (Kraus, 2004: 8).

Si bien la enfermedad es una especie de tierra inhóspita de la cual se quiere regresar o bien transitar de manera rápida, también es cierto que la introspección que da ese espacio, en el que todo parece detenerse debido a la enfermedad, otorga otras posibilidades. Las narradoras caen en la cuenta de que no hay futuro posible, no hay retorno al mundo de los sanos y así pues deben permanecer en el reino de la enfermedad con un mínimo de dignidad.

En Historia del rey transparente, Leola cae herida por la guerra en múltiples ocasiones. Algunas veces, dichas heridas se infectan y enferma con fiebre. Como se sabe, en la Edad Media presentada en la novela, poco o nada se podía hacer ante una infección. Así, Leola siente que se quema, pero lo único que puede hacer es dejar pasar el tiempo. "Hierve mi cuerpo con la fiebre. Y mis piernas pesan como troncos caídos. Mi costado palpita, ahí donde recibí la estocada... No me interesa vivir. Lo que más aprecio de la calentura es el oscuro torpor [sic] en el que te sumerge. Es algo semejante a no existir" (Montero, 2005: 226). El lenguaje que utiliza la narradora para describir la fiebre hace alusión a algunas de las metáforas que Sontag señala en La enfermedad y sus metáforas. La fiebre es un abrasamiento interior que tiene un dejo romántico, a la vez que punitivo. $Y$ la segunda parte de la cita remite a la mortalidad. "La propia enfermedad aparece como metáfora de la mortalidad, de la fragilidad y vulnerabilidad humanas" (Sontag, 2003a: 131). Así, Leola se consume, no se sabe si por las pasiones prohibidas al ser una mujer caballero y no poder tener una 
pareja o una relación íntima, o por la culpa de estar engañando a todos con su disfraz o bien, por haber matado a tantos hombres al convertirse en mercenaria durante un tiempo.

Además de todo, cuando Leola enferma debe cuidarse de que no descubran su verdadera identidad. No puede ser vista en la intimidad por quiénes la atienden porque en seguida notarían que es mujer. Así, su máxima preocupación es siempre ésta, y no la enfermedad en sí. "-Nyneve, ¿̇cómo es posible que no hayan advertido que soy una mujer? -Sólo te he cuidado yo. Y prohibí que te viera ningún médico" (Montero, 2005: 111). En esta cita se observa con claridad lo desarticulada que se encuentra Leola al verse no sólo como enferma, sino como un ser escindido y vulnerable que tiene dos caras, una de las cuales, resulta peligrosa. Quizás sospecha que el castigo sería ejemplar e incluso peor que yacer enferma. Pero a la vez, esto es metáfora del enfermo, pues quien está aquejado por un mal, no puede verse con claridad, su cuerpo está además de descompuesto, irreconocible.

Un milagro en equilibrio de Lucía Etxebarria muestra la enfermedad desde el punto de vista de quien sufre por ver al enfermo debatirse entre la vida y la muerte. Es decir, aquí la protagonista se convierte en espectadora, en un receptor cuya conciencia le muerde ya que poco o nada puede hacer por la madre enferma. Además, la narradora sufre una transformación, pues ella, la hija, se convierte en la guardiana y cuidadora de la madre enferma. Dicho cambio puede ser visto normal dentro de las vidas de las mujeres, al llegar las madres a la vejez, sin embargo, es importante esta transformación del personaje porque la protagonista no es cercana a la madre. Eva está alienada de ella, siente que no la comprende y que la madre pertenece a una generación de mujeres en una España anquilosada y franquista, tradicional y católica, que no tiene nada que ver con la suya. Sin embargo, la experiencia de la madre enferma va cambiando algunos de sus prejuicios, o al menos le abre nuevas rutas de entendimiento. Aunado a esto, la narradora experimenta sentimientos de tristeza, simpatía y solidaridad ante la enfermedad de la madre que la acercan a ella. Se da cuenta de cuán banal ha sido toda esa batalla contra ella, cuán inútil es pelear cuando la vida es tan frágil. Es como si el desamparo de la madre las hermanara.

Mothering is an intimate kind of caring that has as its goal the creation of capable members of the larger community. It sometimes feels a lot 
like the kind of caring, intimate work we do with people that are sick or very elderly and frail. ...But there is a sadness in our care of the elderly, and sometimes of the very sick, because we know we are easing the passage out of life (Katz Rothman, 1989: 9) ${ }^{1}$.

Las circunstancias de Eva son éstas. Por una parte, ella es la madre que cuida, nutre y crea nexos con su hija Amanda y, por otra, ante la gravedad de la madre debe permanecer a su lado en vela, ayudándola a transitar hacia la muerte. He ahí la ironía: la vida que comienza con el nacimiento de su hija y la vida que se va con la muerte de su madre, ambas enlazadas de forma inextricable a la narradora. La continuidad de la existencia se ata irremediablemente en ella convertida en puente entre ambas generaciones. Así pues, comienza a narrar a la hija la vida de la madre, esa abuela que ya no va a conocer.

En el hospital en el que yace la madre enferma se encuentra Eva con su hermana, con la que no se entiende, pero de igual forma debe convivir con ella dadas las circunstancias, más incluso que con el padre o el hermano que aparecen casi de forma artificial en el hospital, distraídos e incómodos, fuera de sitio, como si la enfermedad y la muerte fuera sólo el reino de la mujer. “... in any given society, feminine personality comes to define itself in relation and connection to other people more than masculine personality does" (Chodorow, 2001: 44) ${ }^{2}$.

El otro personaje que aquí aparece y se conecta con Eva es la enfermera, quien además no lleva cualquier nombre, pues se llama Caridad ${ }^{3}$. Más que los médicos con sus recetas, sus pronósticos y sus exámenes, es Caridad la que abre una válvula de escape a través de la cual pueda desahogarse la protagonista. En Caridad puede confiar para que la madre se encuentre

1 "La protección maternal es una forma de cuidado íntimo que tiene su objetivo en la creación de miembros capaces dentro de la gran comunidad. En ocasiones se siente en parte como el trabajo que hacemos en el cuidado de los enfermos o los muy mayores y frágiles. ... Pero hay una tristeza en nuestro cuidado de los ancianos, y a veces en el de los muy enfermos, porque sabemos que estamos aligerando su paso fuera de la vida".

2 "...en cualquier sociedad, la personalidad femenina se viene a definir en su relación y conexión con otras personas más que la personalidad masculina”.

${ }^{3}$ La caridad dentro del sentido del catolicismo tiene que ver en parte con la ayuda a los enfermos. Este tipo de servicios está muy relacionado a con las monjas, sanadoras tradicionales dentro del mundo eclesiástico. 
cómoda, limpia y con dignidad. Es ella quien le explica que al estar estable no sufre, y así Eva encuentra un cierto consuelo, aunque el dolor que siente le resulte constante. "Es un dolor estable, como su condición, que no se manifiesta ni a gritos, ni a lágrimas, que se lleva por dentro sin enseñarlo por fuera, cuando el corazón se va derramando poco a poco y sin querer, como una olla rota" (Etxebarria, 2004: 258).

Eva, sin embargo, se rebela ante lo que ocurre, le cuesta aceptar lo que pasa, sobre todo porque se siente culpable por no haberse acercado antes. La madre no entiende a la hija y la hija no la entiende a ella, es el clásico ejemplo de choque generacional, pero así se han mantenido casi desde la adolescencia de Eva, por lo que este momento de la enfermedad de la madre la confronta con ese pasado y esa distancia. Ahora intenta resarcir el pasado. Así, el grave estado en el que está su progenitora se vuelve aún más terrible porque quisiera decirle lo que antes no ha podido. Por otra parte, por primera vez en su vida, Eva muestra admiración por la madre. Se da cuenta de que a pesar de las restricciones sobre la condición de la mujer en la época que le tocó vivir, la madre siempre ha luchado, incluso ahora al borde de la muerte.

-No es cierto que desees morir -masculla-. Luchas como un león en todos los combates. De nuevo la pesadilla que se muerde la cola: hay que recurrir a los antibióticos para intentar atajar la infección, pero los antibióticos son tóxicos y están dañando los órganos vitales (Etxebarria, 2004: 180).

Es evidente así la frustración de Eva, quien queda como mudo espectador del desenlace de la vida de la madre. Si antes la comunicación era poca por el escaso esfuerzo de ambas en lograrla, ahora se vuelve imposible por la enfermedad. Así, el estado emocional de Eva se empieza a transformar, porque de pronto se ha dado cuenta de cuánto necesita a su madre, y de que no quiere perderla. Eva comprende que el sentido de identidad que la conecta con su madre es el mismo con su hija, y que aquello que la separó de la madre durante años es algo superficial. Además, Eva admira la resistencia de la madre a la muerte y a la enfermedad, cada día que pasa es un día que vence. Esta es la misma resistencia que admira Nyneve en Leola cuando ésta es herida y sigue luchando por vivir.

Caridad le muestra a Eva que lo que importa es el día a día, la fuerza 
que hay en la lucha por sobrevivir o resistir como explica Sontag (2003b). "Piensen que hoy sigue aquí, y eso es bueno. No intenten pensar en cómo va a ser mañana, sólo en que hoy sigue aquí, que resiste” (Etxebarria, 2004: 205), les dice a las hermanas. Así, la vida al final de todo se convierte en eso, en el presente. Ya parece haber acabado esa loca carrera por obtener el futuro, el éxito, un objetivo. La vida es como dice Caridad: lo que hoy está. Para el final de la novela, Eva obtiene una visión más amplia de la vida a partir de su relación con la madre enferma. La enfermedad no corre, no compite, simplemente se transita en ella

Por último, en la relación que Eva establece con el cuerpo de la madre enferma no deja de haber una metaforización a través de ciertas ideas en torno a la tuberculosis como las que menciona Sontag, sobre la belleza física adquirida por quien padece este mal. En esto, la novela adquiere un tono romántico como La dama de las camelias de Dumas. Parece como si la enfermedad le diera un aire de dignidad, belleza y armonía. "Este aspecto lánguido y enfermizo no mermaba su belleza, más bien al contrario: de la enfermedad le venía la extrema delgadez y el aire elegante y delicado" (Etxebarria, 2004: 298). Pero la narradora es consciente de que tal aspecto y tal relación con la belleza o elegancia, que raya en lo etéreo es en sí sólo una imagen metaforizada del cuerpo de la madre. Y esto se lo aclara a Amanda por escrito como si se corrigiera a sí misma de su comentario anterior. "Lo que sucedió en el cuerpo de tu abuela se parece mucho a lo que sucede en el entorno del enfermo. Se vuelve a aplicar ese viejo axioma de la sociología del cuerpo como metáfora de la sociedad" (Etxebarria, 2004: 308). Sin embargo, dicha metáfora funciona como conexión entre ellas; de pronto, la hija admira a la madre, incluso sabiendo que es una construcción la que ha hecho, el pensar en su madre en esos términos la reconcilia de algún modo, piensa en su madre como luchadora, como fuerte, hermosa, etc. "La vía de la belleza es, junto a la de la desgracia, una puerta abierta a lo sobrenatural” (Tommasi, 2010: 51). En ello viene la aceptación del otro. El lazo que se había distanciado, se acorta. “... daughters are likely to participate in an intergenerational with their mother, and often with their aunts and grandmother" (Chodorow, 2001: 57)4. De alguna forma, durante la es-

4 “... las hijas son aptas a participar de forma inter-generacional con la madre, así como con las tías y abuela”. 
tancia de la madre en el hospital, ambas se van acercando entre sí, forman parte de un ritual común, heredado.

\section{El cuerpo negado y la muerte}

Dentro de la cultura occidental la muerte es temida, poco aceptada. La expulsión de Adán y Eva del Paraíso terrenal y su entrada en la mortalidad es vista bíblicamente como castigo al desacato de los hombres. Las principales religiones de occidente traen consigo esta metáfora sobre la muerte y la salida de la condición perfecta anterior a la mortalidad. Por otra parte, hoy en día, cuando el mercado rige los parámetros de la vida, el éxito y la belleza, en los que la imagen es el arquetipo de la juventud y se invierten millones de dólares en esta industria -como explica Gilles Lipovetsky (2004)la enfermedad, el dolor y la muerte representan justamente lo opuesto: el enemigo a vencer. "En las culturas conformadas por la industrialización, en las grandes ciudades, la enfermedad y la muerte se consideran, a menudo, enemigos" (Caycedo Bustos, 2001: 335). La muerte así, es el tema del que no se habla. "No es fácil hacer frente a la muerte, quizás porque hemos hecho de ella un tabú" (Caycedo Bustos, 2001: 337).

En Historia del rey transparente, Leola se enfrenta por vez primera a la muerte a través del señor de Ballaine, llamado así a través de la novela, su maestro en las artes de la caballería. Éste, sabiendo que su hora se acerca, primero la entrena, luego la aconseja y finalmente, le dice que se marche porque él está a punto de fallecer y desea hacerlo solo.

... los ancianos son considerados animales inútiles y enfermos de los que uno debe desembarazarse. Pero yo sé que eso no es así. Yo sé que la vejez es la verdadera etapa épica del hombre, es la edad en la que los guerreros debemos librar nuestra batalla más gloriosa. No hay gesta mayor, no hay mejor proeza que saber envejecer y morir bien (Montero, 2005: 42-43).

Aunque el señor de Ballaine debe esconderse para morir con cierta dignidad dados los tiempos que se viven, está seguro de que morirse no es vergonzoso, sino sólo una batalla más. Con su muerte enseña a Leola a no temerle. Es tal la idea de que la vida siempre es más valiosa que la muerte, 
que ésta parece tener necesidad de esconderse, no se permite morir, no se permite hablar de ello, ni mostrarlo. "One might say that the ancient right to take life or let live was replaced by the power to foster life or disallow it to the point of death" (Foucault, 1978: 138)5. Pero el señor Ballaine, al hablar francamente con Leola sobre la muerte, muestra que es inútil esa lucha, a la vez de fútil. "The body in death highlights the passage of time, the inevitability of physical transformation, and thereby acts as a powerful reminder that the self is subject to death" (Hallam, Hockey \& Howarth, 1999: 4) $)^{6}$ La muerte de un ser querido es parte de su biografía, así lo entiende Leola al marcharse para dejar a su maestro y también lo comprende al adoptar a Guy -el hijo con discapacidad mental de su maestro- más adelante.

Tras perder al maestro Ballaine, Leola conoce en el bosque a Nyneve, quien luego se convertirá en una especie de escudero, una madre y por último, una fiel amiga de Leola. Tras librar varias batallas y aventuras, y acabar encerradas en medio de la persecución iniciada por la Inquisición, Nyneve -ya envejecida- decide morir antes de que entren sus perseguidores. Nuevamente, a partir de la despedida, Leola aprende de Nyneve cómo enfrentar la muerte.

-No llores, Leola... La Cábala, que es un saber profundo y antiguo, dice que el mundo es una isla de infelicidad en un mar de gozo. Sólo estoy escapando de esta isla de infelicidad en la que ahora mismo estamos atrapados... Pero el gozo existe y es mucho más fuerte y más abundante. Regresaremos y seremos millones ${ }^{7}$ (Montero, 2005: 506).

Por medio de la espiritualidad, Nyneve resuelve el nuevo estado en el que se convertirá al morir. No cree en la muerte como finitud. "At times the dead become 'embodied' through the materialization of a spirit or ghost"

5 "Uno podría decir que el antiguo derecho de tomar la vida o dejar vivir ha sido reemplazado por el poder de alentar la vida o no permitirla al punto de la muerte".

6 "El cuerpo en la muerte pone en relieve el pasaje del tiempo, la inevitabilidad de la transformación física, y así se convierte en un poderoso recordatorio de que el ser está sujeto a la muerte".

${ }^{7}$ La última frase de la cita ha sido atribuida a diversas personalidades y ciertamente una de sus tradiciones es la Edad Media, pero no se le puede adjudicar de forma definitiva a alguien. 
(Hallam, Hockey \& Howarth, 1999: 13) ${ }^{8}$. Es decir, que lo que la mantiene con esperanza es la creencia de que aunque se pierda el cuerpo queda el alma y con el alma se puede regresar. La espiritualidad de Nyneve, si bien es comparable a la religiosidad, en la que se visualiza la resurrección o incluso, la reencarnación -ambas son posibles con la frase dicha "regresaremos y seremos millones"- tiene connotaciones de vida después de la vida en un sentido más amplio que el religioso, de concreción de ideales, de gentes, espíritus que volverán en un futuro, pero al no mencionar a Dios, parece abarcar más bien una cuestión metafísica encarnada en sí misma, y no en religión alguna. Tiene fe en el regreso, y ese regreso es espiritual, no religioso. Esa certeza que le brinda Nyneve, ayuda a Leola a tomar la decisión de hacer lo mismo con ella y Guy cuando ya el destino trágico que se avecina es inevitable. Finalmente Nyneve muere:

Ayudada por las Buenas Cristianas, arrojo el bulto, la cáscara vacía, la apariencia de mi amiga, a la corriente tumultuosa. Al caer, salpica. El agua está helada. El cuerpo da unos cuantos tumbos, se hunde, vuelve a emerger, desaparece flotando cauce abajo. Rugen las aguas bravas... Hace tanto ruido que me impide escuchar el alegre bisbiseo de las palabras de Nyneve en Avalon (Montero, 2005: 508).

El cuerpo de Nyneve es cáscara, el sustento se ha ido para regresar en el futuro. El cuerpo es transformado en mero envoltorio; el cadáver es algo que se desintegra que deja de ser la persona para pasar a ser mero desecho. Nyneve ya no es. Y aunque no deja de ser triste la escena que presenta la narradora, es evidente que lo que busca ya no está en el cadáver, sino en el sonido de sus palabras que vienen del otro lado del mundo, en el más allá. "Cuando muere, cuando ya no es cuerpo. Cuando es cadáver ya no es al mundo. Al separarse del mundo en el momento de la muerte, deja de ser cuerpo; o mejor, al dejar de ser cuerpo, el mundo deja de ser tal" (Pfeiffer, 1998: 141). El poner el cuerpo vacío de Nyneve en el agua resulta tan simbólico como si fuera cremado, finalmente uno de los cuatro elementos de la vida se hará cargo de su muerte para llevársela y transportarla a Avalon o tasma”.

8 “En ocasiones la muerte se 'encarna' en la materialización del espíritu o el fan- 
al Paraíso. Es el regreso del héroe al hogar. Los rituales de despedida involucran muchas veces los elementos: fuego, agua, tierra, aire. “... death and its rituals not only reflect social values but also shapes them in important ways" (Hallam, Hockey \& Howarth, 1999: 4) ${ }^{9}$. Hay una especie de renovación en el acto de morir y regresar a los elementos; se limpia lo sucio, se libera el cuerpo y el cadáver tiene como propósito alimentar la tierra, volver a la naturaleza de donde surgió.

Tras la muerte de Nyneve, Leola se prepara para la suya. Toma la decisión de creer en Nyneve y de irse antes de que los cruzados derriben el lugar. Nyneve ha dejado parte del elixir para ella y Guy, con éste regresará a ese lugar mágico como se ve en alguno de los trampantojos pintados por Nyneve. Pero antes debe terminar su escrito, el que escribe a matacaballo usando todos los cabos de vela que quedan en esa noche insomne. El escrito es su legado, pero antes funciona como su catarsis y su forma de controlar el miedo a la muerte. “¿Por qué cuesta tanto morir, si no cuesta nacer? ... Los días se han deshecho entre mis manos como copos de nieve. Qué poco dura el sueño de la vida” (Montero, 2005: 511). Y en estas líneas, la narradora recuerda o emula al poeta latino Virgilio, el tiempo que se va, el tempus fugit que intenta recuperar la vida y vivirla al máximo. A la vez, las líneas tienen el recurso poético-filosófico que adopta Calderón de la Barca en La vida es sueño. Ahora que Leola está por acabar su texto, siente que todo ha sido muy rápido y efímero, siente nostalgia, pero a la vez valor. Empieza a tomar el elixir y se queda suspendida entre la vida y la muerte, ¿escribe? Al parecer, sí, pero ya falta poco para que caiga, son quizás sus últimas palabras.

Ahí está Nyneve, una Nyneve joven y delgada de cabellera llameante. Un grato sopor cierra mis ojos; me parece sentir sobre los párpados los ligeros besos con los que León me ayudaba a dormir en las noches inquietas. Me marcho a la Isla de las Manzanas, me voy con Nyneve, y con Morgana le Fay, la bella y sabia bruja. Con Arturo, el buen Rey, que allí se repone eternamente de sus heridas; con la Hermosa Juventud, rescatada de la derrota y de la muerte. Pero no nos iremos lejos. Estaremos en las sombras que se deshacen cuando las miras de frente... en el poderoso

9 “... la muerte y sus rituales no sólo reflejan valores sociales, sino que les da forma de formas importantes”. 
zumbido de la vida que se escucha dentro del silencio de nuestras cabezas (Montero, 2005: 513-514).

Alude a los fantasmas de los muertos, los espíritus de los que la han dejado. Los necesita para irse. De pronto, Leola encarna de nuevo a Nyneve, la ve o imagina en la pintura que ha dejado atrás. Asimismo, revive las leyendas medievales de su época, las encuentra en la muerte o más bien la encuentran a ella tras tomarse el elixir. El lector no tiene una explicación racional para lo que Leola experimenta, pero a la vez -como todo lo que atañe al cuerpo- la experiencia de la muerte es solitaria, no se puede compartir. Lo que se intuye es que en la transición del cuerpo al cadáver quedan estas imágenes mentales producto de la ensoñación o la bebida, pero de cualquier forma reales para quien las relata. Al final queda la idea de que la fuerza de la vida se sobrepone a la muerte porque todo es, al fin, una sola y larga cadena que forma la humanidad.

En Un milagro en equilibrio de Lucía Etxebarria la muerte aparece en la figura de la madre que vela Eva, la hija. Sin embargo, antes de que ocurra eso, ya Eva mira la muerte o más bien, la descubre en su entorno, por ejemplo en el metro con un enfermo de SIDA que descubre, famélico y demacrado, al que la gente le rehúye. "A la gente le hace ilusión ver una nueva vida, pero no aguantan ver la muerte cerca: les recuerda demasiado la inevitabilidad de la suya" (Etxebarria, 2004: 207). Así compara el recibimiento que tuvo Amanda con la soledad de la muerte que poca gente acompaña en nuestra sociedad contemporánea cada vez más obsesionada por la juventud. "Hay pueblos que miran el fin de sus días con miedo y soslayo, como los países más civilizados de Occidente, que en la actualidad se rehúsan a hablar de los muertos, quizás por la influencia hedonista de la publicidad” (Caycedo Bustos, 2001: 333).

Eva encuentra en la enfermedad de la madre y en el nacimiento de la hija dos visiones distintas del tránsito de la vida, una hacia ella para encarnarla, y otra, fuera de ésta para dejarla. La muerte es lo que no se comprende, está más distante del humano que el nacimiento. Nacer es llegar a la vida, al mundo, al espacio conocido y ello produce alegría, pero la muerte es un paso a lo desconocido, al no lugar y por ello se niega. "De la misma manera en que no vemos gordas en las revistas de moda ni en los programas de televisión, tampoco vemos la muerte a nuestro alrededor. Ya nadie 
o casi nadie lleva luto y nunca se habla de los familiares muertos, como si no existieran" (Etxebarria, 2004: 296). La muerte es vacío, el cuerpo que se apaga, es un tabú que sólo toma relieve cuando ocurre de forma cercana.

Cuando Eva comienza a visitar a su madre en coma en el hospital se da cuenta de que está en una especie de limbo en el que no es ni cuerpo, ni cadáver, sino espera de que algo suceda. "For example some individuals have become categorized as 'just vegetables', a product of social practices and discourses, which in shaping the self in relation to the body in death, produce forms of social exclusion" (Hallam, Hockey \& Howarth, 1999: 1) ${ }^{10}$. La madre está excluida de la vida. Además se ha vuelto dependiente como si fuera un niño, tanto como Amanda, quien acaba de nacer.

Resulta curioso cómo la vejez acerca a los humanos al estado de bebé. Porque ahora ella es como tú: incapaz de moverse o incluso de sobrevivir sola. Y, sin darnos cuenta, sin querer, sin pensarlo, todos le hablamos como a un bebé, empleando un tono agudo al dirigirnos a ella y moviendo exageradamente la boca (Etxebarria, 2004: 297).

Eva le habla a la hija, le escribe sobre su abuela gravemente enferma, le explica cómo ha dejado de ser persona. Como no oye o más bien no responde, le hablan como si fuera niña, aunque no lo sea. Está en un lugar distinto, en donde las cosas no funcionan igual. Eva no sabe cómo tratarla, la idea de la muerte la desconcierta. La madre se ha convertido en un "otro" que no conoce. No es la madre, pero a la vez lo es. No está muerta, pero tampoco está viva. La prolongada enfermedad la mantiene en un vacío confuso.

Represented in this way, such individuals come to be constructed as "other". They are seen to have lost their place in society and now find themselves accommodated among individuals who have never had one -for example, people who have had long institutional lives as a result of physical and mental disability (Hallam, Hockey \& Howarth, 1999: 39) ${ }^{11}$.

10 "Por ejemplo, algunos individuos han sido clasificados como 'vegetales', como producto de prácticas sociales y discursivas, que en la construcción del ser en relación al cuerpo en la muerte, produce formas de exclusión social”.

${ }_{11}$ "Representados de esta manera, los individuos son construidos como 'otro'. Son vistos como seres que han perdido su lugar dentro de la sociedad y ahora se encuentran acomodados entre los individuos que nunca han tenido un sitio -por ejemplo, la gente que ha llevado largas vidas dentro de instituciones como resultado de discapacidades físicas y mentales". 
El avance cada vez más acelerado de la medicina ha servido para prolongar la vida, pero también, por medio de esa misma tecnología, ha creado espacios disasociados en el que convergen enfermos y parientes sin saber a ciencia cierta cómo comportarse. El sufrimiento parece prolongarse, al igual que la despedida. La tecnología diseña espacios para seguir vivos, pero de forma artificial, creando dilemas éticos para pacientes, familias y médicos. ¿Es mejor siempre la vida? La novela de Etxebarria parece indicar que no, que ese no lugar resulta demasiado doloroso e insoportable. "Es cierto que yo me siento muy culpable, culpable, por ejemplo, de desear que todo acabe de una vez. Ya he perdido la esperanza, ya entiendo que mi madre no va a sobrevivir y no le veo el sentido a alargar esa agonía innecesariamente" (Etxebarria, 2004: 322). Después de mucho tiempo, un tiempo que la narradora ha tratado de llenar con un texto que en parte narra la vida de la madre, donde busca refugio y reconciliación, la madre muere una noche. Cuando suena el teléfono, ella ya lo sabe. En la llamada viene el derrumbe, pero también el descanso.

Eva va al hospital y pide ver a la madre muerta antes de que la arreglen, antes de que la recompongan. Los embalsamadores de cuerpos arreglan los cadáveres para asemejar lo que la gente recuerda de ellos con vida, son una imagen, una marca, una subjetividad que los vivos necesitan para despedirse, ya no se les quiere ver convertidos en el saco de huesos que fueron al final o contemplar las imperfecciones adquiridas con la enfermedad. Los seres queridos desean ver al muerto como era antes o como creen que era. "... the corpse is prepared by morticians who employ the language of identity and personality, projecting desires such as clothing choice and hairstyle onto their subjects. Striving to produce a body which closely resembles the living body remembered by survivors" (Hallam, Hockey \& Howarth, 1999: 12) ${ }^{12}$. Pero Eva quiere confrontar la muerte tal como vino y pide a Caridad que le muestre a la madre, quien ya está dentro de una bolsa.

Caridad abrió la cremallera y entonces vi a mi madre sin mi madre, a su envoltura mortal (porque me vino a la cabeza de inmediato aquella frase

12 “... el cuerpo es preparado por los embaladores que emplean el lenguaje de la identidad y la personalidad, proyectando los deseos de vestimenta y peinado de sus sujetos. Intentan producir un cuerpo que asemeje el cuerpo vivo recordado por los sobrevivientes". 
de Hamlet: this mortal coil ${ }^{13}$, blanca, fría, muy helada, pero no rígida aún, porque pude cogerle aquella mano aterida pero todavía flexible y apretarla contra mí, y sólo en aquel instante me di cuenta de que aquello ya era irreversible, de que a partir de ese momento ya sólo me quedaría recordar cómo era el tono de su voz, de qué manera sus gestos, sus palabras o sus silencios (Etxebarria, 2004: 340).

Otra vez se ve aquí el caparazón tal y como lo utilizó Montero con el cuerpo de Nyneve que se convirtió en cáscara. No hay vida, sólo envoltorio. Ver el cuerpo así es la certidumbre de la muerte fuera de la ilusión creada por el embalsamador de cuerpos. Esta es la verdadera muerte sin disfraces. Ya no está. Ahora empieza a ser misterio, y memoria para Eva. No sabe a dónde fue, pero la tiene viva en el recuerdo y en el texto que ha escrito. Eva llora y se da cuenta de que la madre le dio la vida, literal y simbólicamente tal y como ella con Amanda, y que en ese misterio hay una conexión en la que se empuja por la vida en contra de la pulsión de la muerte. "Y a esa pulsión de muerte yo la llamé Mi Otra. Y la Otra, que había nacido del amor a mi madre, se quedaba allí, impotente frente a una bolsa verde, viendo cómo la razón de existir que la animara se reducía a eso, a un envoltorio" (Etxebarria, 2004: 341). La protagonista se siente escindida al ver a la madre, como si fuera dos, una es la muerte y la otra es la que se despide de la madre que ha muerto.

Finalmente es a partir de la muerte que se percibe dentro de los textos que las narradoras adquieren una visión distinta de sus vidas y de las de sus seres queridos. La muerte está a la vista y no a puertas cerradas, hay un coraje en esa mirada sin tapujos que parece perfilarse como reflejo contestatario ante una sociedad de ojos y oídos cerrados, envuelta en sí misma y en la banalidad de la moda o los medios, incompatibles con lo grotesco de la muerte.

En estas obras la muerte es un paso más dentro de la vida, tanto como nacer. No pertenece a las tinieblas, aunque dé miedo; no es oscuridad aunque cause zozobra, simplemente es algo que tiene que pasar y es el cambio de un estado a otro. Así pues, la forma en la que se maneja la muerte en los

${ }^{13}$ Shakespeare se refiere aquí al caparazón que es el cuerpo que parece enrollarse o vestir al ser. 
textos tiene que ver con la dignidad con la que ocurre. Vivir y morir con dignidad parece ser la consigna.

\section{Conclusiones}

Como se ha observado el tema de la enfermedad, el dolor y la muerte en estas dos novelas españolas de reciente publicación es pertinente y muestra, lejos de tabúes o idealizaciones románticas, lo que significa la transgresión del cuerpo en la enfermedad, el dolor y la muerte. En Un milagro en equilibrio a través de la madre de la narradora enferma y que al final muere, y en la otra, en la experiencia propia. En casi todos los ejemplos vistos, la enfermedad no se metaforiza, sino se ve como lo que es: una condición del cuerpo. Susan Sontag (2003) ha escrito en La enfermedad y sus metáforas cómo durante años se ha visto la enfermedad o el cuerpo como parte de un castigo o expiación. El significado de esto se remonta a ejemplos bíblicos como las plagas o como en la literatura greco latina en la que la peste era un castigo por transgredir un orden. Así, y hasta nuestros días, la enfermedad es culpa del enfermo. Sin embargo, estas novelas se alejan de la metáfora.

La escritura de las narradoras sobre sus cuerpos en una especie de bitácora o diario se traduce en un entendimiento mayor sobre su condición. En parte, el cuerpo es aceptado por el acto de escritura y la interpretación que hacen de sus vidas, lejos de las metáforas ancestrales sobre enfermedad y muerte.

En Historia del rey transparente, la enfermedad o las heridas de batalla en Leola, le mortifican más que por la aflicción misma, por el temor a ser descubierta. Es por ello que sólo Nyneve la cuida. Hacia el final de la novela, cuando Nyneve y luego, ella misma, desean morir mediante una bebida antes que morir quemadas en la hoguera, trastocan el significado de la pira. Los mártires cátaros que mueren quemados son respetados por éstas, pero ninguna de las dos cree -como los inquisidores- que a través de la quema de sus cuerpos se van a redimir del pecado de transgredir el orden social. Es por ello que escogen no morir así. Para ellas no hay un acto heroico en morir, sino en poder hacerlo con dignidad; es sólo un paso de tiempo, de etapa, pero no una honra. La muerte es el fin de la vida y el cuerpo, el recipiente de la misma, que una vez sin éste, termina su función. 
Ambas plantean el cadáver también como cáscara, algo que envuelve la vida, pero que no es la vida. $\mathrm{Al}$ ver a su madre muerta dentro del saco de plástico que abre Caridad para ella, Eva comprende que ya no está y que no puede volver. Cuando Leola avienta el cuerpo de Nyneve al agua dice lo mismo. No es el cadáver de la madre lo que la conecta a Eva con su madre, ni siquiera la enfermedad misma; lo que finalmente la acerca a comprender la vida de la madre es la escritura sobre la vida de ésta. La memoria de la madre es lo que la hace comprender su vida y perdonarla. Igualmente, para Leola, la vida de Nyneve tiene sentido al recordarla y el cadáver que luego da tumbos en el agua ya no la representa.

Por último, en estas novelas se observa que el cuerpo, lejos de ser un tabú con una carga metafórica, se vuelve carne que palpita y sufre, que se ve y que por ende, existe. A través de estos cuerpos se da la vida y la muerte, así como la enfermedad y el dolor. El cuerpo no se esconde, sino que se muestra y al hacerlo, se revela en su realidad de enfermedad, dolor, herida y finalmente, muerte. La vida transita a través de estos cuerpos que sufren, que sienten, que luchan. Hay una especie de entereza humana y dignidad que surge de ellos mucho más heroica que las metáforas punitivas o gloriosas con las que anteriormente se narraba la enfermedad y la muerte. La resistencia callada de estos cuerpos pone en relieve la huella de la vida y las señas que la definen. De tal manera que estas novelas acaban por mostrar de una manera más honesta y cercana lo que es vivir en el dolor, la soledad de la enfermedad y el sufrimiento, así como el paso hacia la muerte. El cariz con el que lo hacen reformula desde la literatura la óptica de la enfermedad, quitándole investiduras y tabúes.

\section{Referencias}

Caycedo Bustos, M. L. (2001). La muerte en la cultura occidental: antropología de la muerte. Revista colombiana de psiquiatría, 35(2), 332-339.

Chodorow, N. (2001). Family Structure and Feminine Personality. In Darlene M. Juschka (ed.), Feminism in the Study of Religion (pp. 81-105). New York: Continuum.

Etxebarria, L. (2004). Un milagro en equilibrio. México: Planeta.

Ferrús Antón, B. (2007). Heredar la palabra: cuerpo y escritura de mujeres. Valencia: Tirant lo Blanch. 
Foucault, M. (1978). The History of Sexuality. (Robert. Hurley, trans.). New York: Pantheon.

Glantz, M. (1992). Borrones y borradores. Reflexiones sobre el ejercicio de la escritura (Ensayos de Literatura colonial de Bernal Díaz del Castillo a Sor Juana). México: Universidad Nacional Autónoma de México.

Grosz, E. (1994). Volatile Bodies. Toward A Corporeal Feminism. Bloomington: Indiana University Press.

Hallam, E, J. Hockey \& Howarth, G. (1999). Beyond the Body: Death and Social Identity. New York: Routledge.

Katz Rothman, B. (1989). Recreating Motherhood. New York: W.W. Norton and Company.

Kraus, A. (2004). Las letras como cura. Revista de poesía Alforja, 31, 6-8.

Lipovetsky, G. (2004). El imperio de lo efímero. La moda y sus destinos en las sociedades modernas. (Felipe Hernández y Carmen López, trads.). Barcelona: Anagrama.

Martínez Passarge, M. L. (2001). Poética del cuerpo enfermo. Revista de poesía Alforja, 31, 1-3.

Montero, R. (2005). Historia del rey transparente. México: Alfaguara.

Pfeiffer, M. L. (1998). El cuerpo enfermo. Agora. Papeles de Filosofía, 17(1), 137-149.

Scarry, E. (1985). The Body in Pain: The Making and Unmaking of the World. New York: Oxford University Press.

Sontag, S. (2003a). La enfermedad y sus metáforas. El sida y sus metáforas. México: Punto de Lectura.

(2003b) Resistir. (Aurelio Major, trans.).LaJornada Virtu@l. Disponible en http://www.jornada.unam.mx/2003/o4/11/o14a1mun.php?printver=1

Tommasi, W. (2010). Lo bello como encarnación. En Emilia Bea (ed.), Simone Weil. La conciencia del dolor y de la belleza (pp. 51-62). Madrid: Trotta. 